\title{
Effect of Implementing Nursing Instructions on Patients' Outcomes Undergoing Transurethral Resection of Bladder tumor
}

\author{
Manar Omar Mohammed ${ }^{1}$, Mimi Mohammed Mekkawy ${ }^{2}$, Medhat Ahmed Abdallah ${ }^{3}$, Ghada Hassan Ahmed ${ }^{4}$. \\ 1. Demonstrator, Medical Surgical Nursing Department, Faculty of Nursing, Assiut University, Assiut, Egypt. \\ 2. Professor, Medical Surgical Nursing, Faculty of Nursing, Assiut University, Assiut, Egypt. \\ 3. Professor, Department of Urology, Faculty of Medicine, Assiut University, Assiut, Egypt. \\ 4. Lecturer, Medical Surgical Nursing Department, Faculty of Nursing, Assiut University, Assiut, Egypt.
}

\begin{abstract}
Transurethral resection is a procedure in which bladder tumors can be removed. Aim: Assess patients' knowledge about bladder cancer and transurethral resection, design nursing instructions for patients undergoing transurethral resection and evaluate the effect of implementing nursing instructions on patients' outcomes. Setting: The study was carried out in the Urology Hospital at Assuit University Hospital. Subjects: 60 adult male patients (18-65) yrs old. Patients were divided randomly into two equal groups (study and control) 30 patients for each. The study group was received the nursing instructions while the control group was received the routine care. Research design: Aquasiexperimental research design was used here. Data collection tools: I) Prelpost structured interview questionnaire. II) Pain numeric rating scale. Results: there was statistically significant difference between the study and control groups on knowledge score, and assessment of complications. Conclusion: there was significant improvement post implementing the nursing instructions among the study group. Recommendation: Instructions should be applied to improve patients' condition in simplified booklet.
\end{abstract}

\section{Key Words: Transurethral Resection, Bladder tumor \& Nursing Instructions.}

\section{Introduction}

Bladder cancer is a major cause of mortality and morbidity worldwide, In Egypt, bladder cancer is the second most common malignancy among men and $30 \%$ of the cases are squamous cell carcinoma type, It is 3-4 times more common in men than in women. There were 10,399 people diagnosed with bladder cancer and 5081 deaths from bladder cancer in 2015. The majority of cases occur in people aged over 60 . The main risk factor for bladder cancer is increasing age, but smoking and exposure to some industrial chemicals also increase risk (Amr $\mathbf{S}$ et al., 2015).

Bladder cancer typically presents with gross or microscopic hematuria. Less commonly, patients may complain of urinary frequency, nocturia, and dysuria, symptoms that are more common in patients with carcinoma in situ. Patients with upper urinary tract urothelial carcinomas may present with pain resulting from obstruction by the tumor and other systemic symptoms as fatigue, weight loss, and bone tenderness that can indicate more advanced disease (Ruder et al., 2015).

Most bladder cancers (75-80\%) do not involve the muscle wall of the bladder and are usually treated by telescopic removal of the cancer (transurethral resection of bladder tumor (TURBT). This is often followed by instillation of chemotherapy or vaccine-based therapy into the bladder, with prolonged telescopic checking of the bladder (cystoscopy) as follow-up. Some people in this group who are at higher risk are treated with major surgery to remove the bladder (cystectomy). People with cancer in or through the bladder muscle wall may be treated with intent to cure using chemotherapy, cystectomy or radiotherapy, and those who have cancer too advanced to cure may have radiotherapy and chemotherapy (Zheng et al., 2015).

Transurethral resection of bladder tumor (TURBT) is the first-line treatment to diagnose, stage, and treat visible tumors. TURBT is not effective for carcinoma in situ (CIS) because the disease is often so diffuse and difficult to visualize that surgical removal is not feasible. Therefore, the role of cystoscopy is to establish the diagnosis so that therapy can be instituted (Gary, 2015).

The most common operative complications associated with transurethral resection of bladder tumor are bleeding, bladder perforation and ureteral orifice stricture and these were the focus of the session. Bleeding complications have a reported occurrence rate of $1-4 \%$. Severe bleeding tends to be associated with larger tumors and early deep bladder perforations. Bladder perforation (BP) is the second most common complication associated with transurethral resection of bladder tumor. The mortality associated with an unrecognized intraperitoneal perforation can be as high as $20 \%$ so timely recognition is essential. The management of intra-peritoneal perforation requires bladder repair via laparoscopic approach. Small retrospective studies have shown successful management of intra- 
peritoneal perforations with bladder catheter drainage and an intra-abdominal drain, but this has been performed in carefully selected cases (Andres ,2018).

Nurses play very important role in reducing postoperative complications and providing education for both patients and their families; this includes information regarding symptom management, through providing nursing instructions about catheter care, exercises, diet \& fluid intake, daily activities, medications, referral and follow up and it's important to inform patient about warning signs that indicate urgent hospitalization (Brausi ,2016).

\section{Significance of the study}

Patients with bladder cancer and have TUR-BT have many problems that affect their life style. According to Statistical Report at Assiut University Hospital, the number of patients with bladder cancer was approximately (140) and (128) in 2017.

Nursing instructions for patients has a very important role before, during and after the operation to limit urological complications and improve patient's problems.

\section{Aims of this study were}

1. To assess patients' knowledge.

2. To design nursing instructions for patients undergoing transurethral resection.

3. To evaluate the effect of implementing nursing instructions on patients' outcomes.

\section{Operational definitions}

- Nursing instructions: It refers to the advices that are provided by the nurse and must be followed by the patient regarding dietry instructions, fluid intake and catheter care to avoid possible complications.

- Patients' outcomes: Outcomes measured based on comparisons between both groups (study \&control) regarding outcomes measures which include the patient's knowledge, patient's vital signs and occurance of possible complications.

\section{Research hypothesis}

\section{The current study hypothesized that}

The incidence of transurethral resection complications in patients who will receive the nursing instructions was be less than patients who will receive the routine care.

\section{Subjects \& Method \\ Research design:}

Quasi- experimental design was utilized to conduct this study.

\section{Setting}

The study was carried out at the outpatient clinics in the Urology and Nephrology Hospital at Assuit University Hospital.

\section{Subjects}

Purposive sample of 60 adult male patients in the Urology and Nephrology Hospital at Assuit University Hospital. Age ranged from 18 to 65 years. Patients were divided randomly into two equal groups (study and control) 30 patients for each. The study group was received the nursing instructions while the control group was received the routine hospital care.

The patients, who participated in this study, were selected according to the following criteria:

o Age ranging 21- 60 years.

o Both sexes (male and female).

o Has TUR-BT for at least 3 months and more

o Able to give consent and willing to participate in the study.

o Free from psychological, emotional problems and a chronic disease.

o Free from history of bladder cancer in their family members that might influence the study results.

\section{Sample size}

The sample size was calculated using the epi- info program with confidence level at $95 \%$ and the flow rate of patients 268 cases in 6 months and the sample was calculated to be 60 patients 30 for the study group and 30 for the control group.

\section{Tools}

Two tools were used in this study and developed by the researcher to collect the necessary data for this study.

Tool (I): Prelpost structured interview questionnaire:

It was developed by the researcher based on current national and international literatures. It included five

parts:

Part (1): Socio-demographic data of patients such as name, age, sex, level of education and marital status.

Part (2): assessment of patients' knowledge regarding transurethral resection pre and post (after two weeks) to assess patients' knowledge related to bladder cancer and transurethral resection of bladder tumor; it involves six groups of questions as follows: knowledge about causes of bladder cancer (7 MCQ), knowledge about symptoms of bladder cancer (6 MCQ), knowledge about methods of diagnosis of bladder cancer (6 MCQ), knowledge about possible complications after surgery (6 MCQ), knowledge about complications that require urgent hospitalization after surgery (7 MCQ), knowledge about time of follow up after surgery (6MCQ).

Scoring system:

Every question was given one score for the right answer and zero for the wrong answer or don't know answer. The sum of each group were calculated, then 
the total scores for the patient knowledge were calculated for the total questionnaire, and then categorized into good or poor as follows: $(\geq 60 \%)$ was considered satisfactory and (<60\%) was considered unsatisfactory.

Part (3): Patient's medical data records : medical data as: medical diagnosis and vital signs (temperature, pulse, respiration and blood pressure).

Part (4): Laboratory investigations: (complete blood picture, prothrombine time, international normalized ratio).

Part (5): Assessment of patients' complications: An observation for complications was designed based on related literature. The observation was performed to evaluate the effect of implementing nursing instructions on patients' outcomes with transurethral resection during the hospitalization and follow up for 2 weeks post discharge to observe complications and patients 'outcomes such as (urinary tract infection, hematuria, perforation of the bladder wall, and pain).

Tool (II): Pain numeric rating scale

It was adopted from (Flaherty, 1996) and was used by the researcher to assess pain intensity at the surgery site and around it after the procedure. A scale of 0 to 10 , with 0 being no pain at all and 10 being the worst pain imaginable.

Nursing instructions for patients undergoing transurethral resection

The content of nursing instructions was developed by the researcher based on the literature of review and patients' assessment needs and revised by experts in medical and nursing fields. It included knowledge about transurethral resection of bladder tumor.

It consisted of the following

- Simple anatomical urinary tract overview.

- Information about transurethral resection as definition, indications and complications.

- Preoperative and the day of surgery instructions as deep breathing and coughing exercise \& relaxations techniques.

- Post-operative instructions about diet, fluid intake, catheter care, medications and follow up visits.

- Before discharge general instructions on getting back to work, car driving, returning to usual exercises.

\section{Content validity}

The content validity was done by 5 experts in the field of urological surgery and faculty of nursing, who review the tools for clarity, relevance, comprehensiveness and understanding. The required modifications were made accordingly, and then the tools were designed in their final format and tested for reliability.
Reliability of the tool was measured by Cronbach's alpha coefficient $(r=0.7)$.

\section{Ethical considerations}

An official approval and administration permission were obtained from the head of the urology unit to collect the necessary data. Each patient was informed with the purpose of the study to gain their cooperation. The investigator emphasized that the participation is voluntary; confidentiality will be assured and protection of patients from hazards. Verbal consent was obtained from each patient to his or her contribution in the present study, privacy of the patient was considered.

\section{Pilot study}

A pilot study on $(10 \%) 6$ patients was conducted during March, 2018. Its purpose was to assess the feasibility of the study and clarity of the data collection tools. It also helped to estimate the time needed for filling the questionnaire. The data obtained from the pilot study was analyzed and no modifications were made so, those patients involved in the pilot study were included in the main study.

\section{Field work}

It was conducted through the following phases:

Sampling and data collection were completed during the period from March, 2018 till September, 2018.

The purpose of the study was simply explained to the patients to obtain their cooperation for data collection and conduct the current study, anonymity, confidentiality of patients were assured, privacy of the patient was considered.

\section{Preparatory and planning phase}

To carry out this study, the necessary approval was obtained from the Director of the Urology and Nephrology Hospital affiliated to Assiut University Hospital. All data collected regarding patients' knowledge concerning transurethral resection were interpreted for identifying patients' needs. Data collection was done by the researcher at the out patients' clinic using the pre constructed tools, as previously met. Based on patients' needs and the recent related literatures, an educational instruction was illustrated and written in Arabic-language. It was developed covering knowledge about the following topics including: Brief anatomy of urinary bladder, definition of surgery, brief description of surgery, complications of surgery, nursing care before, during, and after surgery, medication, catheter care, diet, physical activity and exercise, rest, routine and follow up. The researchers design the tools of the study including: prelpost structured interview questionnaire and pain scale tool that were filled in by the researcher. Filling in the tools was completed according patients' understanding and health condition. 
- The appointment for starting educational sessions was scheduled with the patients according to their circumstances.

\section{Implementation phase}

The content of nursing instructions was discussed with the patients in short sessions within two days weekly (Tuesday and Wednesday) in outpatient clinic and urologic department. First assessment patients' knowledge about transurethral resection of bladder tumor, the total number of sessions was three sessions. The number of patients in each session was different according to the flow of patients. Sometimes one patient in a session, two patients in a session, and not exceed more than three patients in a session. Each session's time ranged from 15 to 20 minutes.

First session: was started during first 24 hours post admission preoperatively after patient's hemodynamic stability, the researcher started by introducing herself to the patients telling them aim of meeting, orient patients regarding nursing instructions. Content of this session include; brief anatomy of urinary bladder, definition of surgery, brief description of surgery, complications of surgery, nursing care before, during, and after surgery, medication, catheter care, diet, physical activity and exercise, rest, routine and follow up. The session ended by a summary of its content and feedback from the patients through discussion and questions.

Second session: was started after 24 hours post admission preoperatively, it contains information about complications that may occur and how to solve these problems such as hematuria and voiding problems. Instruct the patient to avoid some foods such as spicy and salty foods and increase fluid intake (one cup of water per hour).

Third session: patient's instructions (Evaluation of knowledge that given for the patients within the previous two sessions):

It includes the following:

- Anatomy of the urinary tract \& the operation: Evaluate patient's knowledge about the anatomy and function of the urinary tract, the meaning, indications, contraindications and complications of transurethral resection.

- Postoperative diet \& fluid intake: Evaluate patient knowledge about the type of food that must be eaten and fluid intake that must be taken after operation.

- Catheter care: Evaluate patient knowledge about the way to care for the urinary catheter after operation to prevent UTIs and other complications.
- Medications: Assess patient knowledge about the new medications needed to be taken after operation and the precautions that should be followed when taking medication.

- Follow up visits and return to the usual activities: Evaluate patient knowledge about the importance of follow up in outpatient urology clinic, the suitable time to return to work, driving the car, return to daily activities and warning signs that indicate urgent consultation \& hospitalization.

- Patients were allowed to ask questions in case of misunderstanding, while listening and expressing interest. The researcher measured the pain scale before and immediately after implementation of the educational instructions.

- At the end of these sessions the researcher emphasized to the participants the importance of the follow up visits.

\section{Evaluation phase}

At the end of the educational instructions implementation evaluation was done to assess its effectiveness for patients who undergo transurethral resection to minimize the possible complications that may occur and improving patient conditions by using the same data collection tools, and comparing the results of the data collected before and 2 weeks after the implementation of the educational instructions.

\section{Administrative Design}

An official letter was issued from the dean of the Faculty of Nursing, Assit University, to the director of the Urology and Nephrology Hospital, explaining the purpose of the study to obtain the permission to conduct this study.

\section{Statistical analysis}

Data entry and statistical analysis were done using SPSS ver. 20 statistical software package. Data were presented using descriptive statistics in the form of frequencies and percentages for qualitative variables, mean and standard deviations for quantitative variables. Independent t-test and cross tabulation was used to the inter-relationships among quantities variables. The level of significance for this study was set as ( p.value $\leq 0.05$ ) to detect any indication of difference found in the data available. 
Results

Table (1): Distribution between the study and control groups regarding their socio-demographic data $(n=60)$.

\begin{tabular}{|c|c|c|c|c|c|}
\hline \multirow{2}{*}{ Variable } & \multicolumn{2}{|c|}{ Study $n=30$} & \multicolumn{2}{|c|}{ Control $n=30$} & \multirow{2}{*}{ P. value } \\
\hline & $\mathbf{N}$ & $\%$ & $\mathbf{N}$ & $\%$ & \\
\hline \multicolumn{6}{|l|}{ Age } \\
\hline $40-60 \mathrm{yrs}$ & 10 & 33.3 & 14 & 46.7 & \multirow[t]{2}{*}{$0.304 \mathrm{~ns}$} \\
\hline$\geq 60$ yrs & 20 & 66.7 & 16 & 53.3 & \\
\hline Mean \pm SD (Range) & \multicolumn{2}{|c|}{$59.40 \pm 6.55(36-64)$} & \multicolumn{2}{|c|}{$59.50 \pm 5.05(43-65)$} & 0.947 \\
\hline \multicolumn{6}{|l|}{ Sex } \\
\hline Male & 25 & 83.3 & 28 & 93.3 & \multirow[t]{2}{*}{$.212 \mathrm{~ns}$} \\
\hline Female & 5 & 16.7 & 2 & 6.7 & \\
\hline \multicolumn{6}{|l|}{ Marital Status } \\
\hline Single & 0 & 0 & 3 & 10.0 & \multirow[t]{2}{*}{$.119 \mathrm{~ns}$} \\
\hline Married & 30 & 100.0 & 27 & 90.0 & \\
\hline \multicolumn{6}{|l|}{ Residence } \\
\hline Urban & 0 & 0.0 & 1 & 3.3 & \multirow[t]{2}{*}{$.500 \mathrm{~ns}$} \\
\hline Rural & 30 & 100.0 & 29 & 96.7 & \\
\hline \multicolumn{6}{|l|}{ Education level } \\
\hline Illiterate & 25 & 83.3 & 21 & 70.0 & \multirow[t]{4}{*}{$.539 \mathrm{~ns}$} \\
\hline Read and write & 4 & 13.3 & 7 & 23.3 & \\
\hline Primary education & 1 & 3.3 & 1 & 3.3 & \\
\hline University & 0 & 0 & 1 & 3.3 & \\
\hline \multicolumn{6}{|l|}{ Occupation } \\
\hline Working & 7 & 23.3 & 10 & 33.3 & \multirow[t]{2}{*}{$.284 \mathrm{~ns}$} \\
\hline Not work & 23 & 76.7 & 20 & 66.7 & \\
\hline
\end{tabular}

Chi-square test

N.s. $=$ Not significant (p. value $>0.05)$

Table (2): Distribution between the study and control group patients regarding their medical data $(n=60)$.

\begin{tabular}{|l|c|c|c|c|}
\hline \multirow{2}{*}{\multicolumn{1}{c|}{ Medical data }} & \multicolumn{2}{c|}{ Study (n=30) } & \multicolumn{2}{c|}{ Control $(\mathbf{n = 3 0})$} \\
\cline { 2 - 5 } & No. & \% & No. & \% \\
\hline Diabetes & 3 & 10.0 & 4 & 13.3 \\
\hline Hypertension & 12 & 40.0 & 4 & 13.3 \\
\hline Heart disease & 1 & 3.3 & 4 & 13.3 \\
\hline COPD & 0 & 0.0 & 3 & 10.0 \\
\hline Diabetes and Hypertension & 5 & 16.7 & 2 & 6.7 \\
\hline
\end{tabular}

Table (3): Comparison between level of patients' knowledge about transurethral resection of bladder tumor obtained by study and control groups after application of nursing instructions $(n=60)$.

\begin{tabular}{|c|c|c|c|c|c|c|c|c|c|}
\hline \multirow{4}{*}{ Level of patients' knowledge } & \multicolumn{9}{|c|}{ After application of nursing instructions } \\
\hline & \multicolumn{4}{|c|}{$\operatorname{Study}(n=30)$} & \multicolumn{4}{|c|}{ Control $(n=30)$} & \multirow{3}{*}{ P. value } \\
\hline & \multicolumn{2}{|c|}{ Incorrect } & \multicolumn{2}{|c|}{ Correct } & \multicolumn{2}{|c|}{ Incorrect } & \multicolumn{2}{|c|}{ Correct } & \\
\hline & No & $\%$ & No & $\%$ & No & $\%$ & No & $\%$ & \\
\hline Causes of bladder cancer & 9 & 30.0 & 21 & 70.0 & 28 & 93.3 & 2 & 6.7 & $<0.001 * *$ \\
\hline Symptoms of bladder cancer & 8 & 26.7 & 22 & 73.3 & 29 & 96.7 & 1 & 3.3 & $<0.001 * *$ \\
\hline Diagnosis of bladder cancer & 2 & 6.7 & 28 & 93.3 & 27 & 90.0 & 3 & 10.0 & $<0.001 * *$ \\
\hline Complications after surgery & 10 & 33.3 & 20 & 66.7 & 28 & 93.3 & 2 & 6.7 & $<0.001 * *$ \\
\hline $\begin{array}{l}\text { Hospital in case of } \\
\text { complications }\end{array}$ & 23 & 76.7 & 7 & 23.3 & 30 & 100.0 & 0 & 0.0 & $0.005 * *$ \\
\hline $\begin{array}{l}\text { Time of follow up after } \\
\text { operation }\end{array}$ & 18 & 60.0 & 12 & 40.0 & 29 & 96.7 & 1 & 3.3 & $0.001 * *$ \\
\hline
\end{tabular}

Chi-square test $* *$ Significant difference at p. value $<0.01$ 
Table (4): Comparison between level of patient's knowledge about transurethral resection of bladder tumor obtained by study and control groups after application of nursing instructions $(\mathbf{n}=60)$.

\begin{tabular}{|l|c|c|c|c|c|}
\hline \multirow{2}{*}{$\begin{array}{c}\text { Level of patient's } \\
\text { knowledge }\end{array}$} & \multicolumn{2}{c|}{ Study $(\mathbf{n = 3 0})$} & \multicolumn{2}{c|}{ Control $(\mathbf{n}=\mathbf{3 0})$} & \multirow{2}{*}{ P. value } \\
\cline { 2 - 6 } & No & \% & No & \% & \\
\hline Unsatisfactory & 4 & 13.3 & 30 & 100.0 & $<0.001^{* *}$ \\
\hline Satisfactory & 26 & 86.7 & 0 & 0.0 & \\
\hline Mean \pm SD (range) & \multicolumn{2}{|c|}{$3.67 \pm 0.96(2-5)$} & $0.30 \pm 0.60(0-2)$ & $<0.001^{* *}$ \\
\hline
\end{tabular}

- Chi-square test $* *$ Significant difference at p. value $<0.01$

- independent T- test** Significant difference at p. value $<0.01$

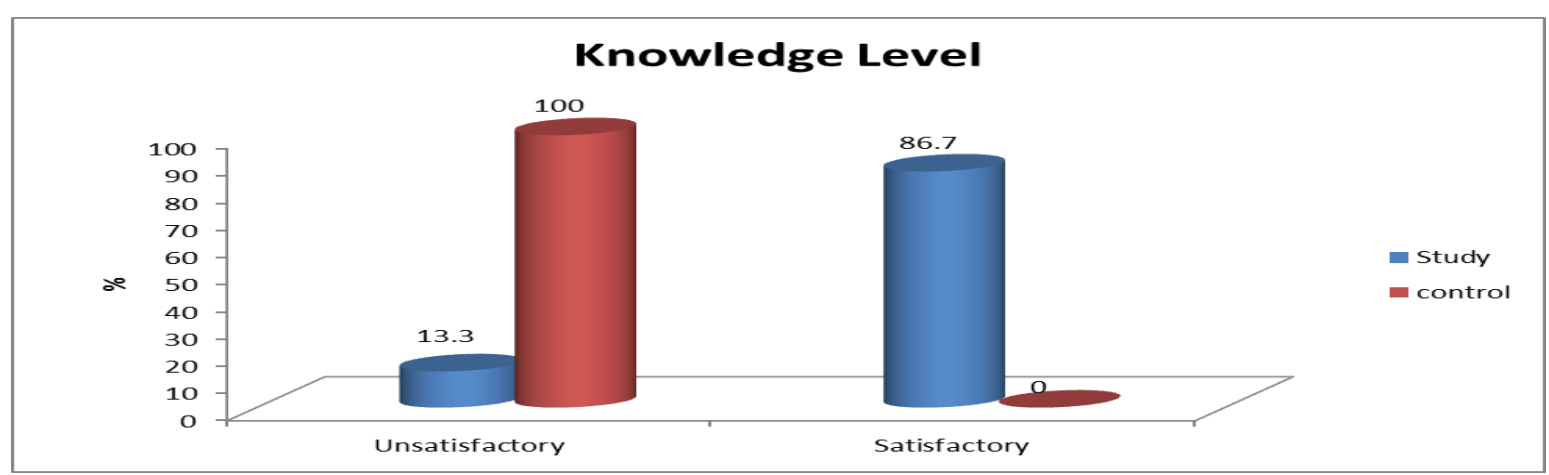

Fig (1): Comparison between level of patient's knowledge about transurethral resection of bladder tumor obtained by study and control groups after application of nursing instructions $(n=60)$.

Table (5): Relation between level of patient's knowledge about transurethral resection of bladder tumor and their socio-demographic data obtained by study and control groups before and after application of nursing instructions $(n=60)$.

\begin{tabular}{|c|c|c|c|c|}
\hline \multirow{3}{*}{ Socio-demographic data } & \multicolumn{4}{|c|}{ Knowledge score } \\
\hline & \multicolumn{2}{|c|}{ Before instructions } & \multicolumn{2}{|c|}{ After instructions } \\
\hline & Mean \pm SD & Range & Mean \pm SD & Range \\
\hline \multicolumn{5}{|l|}{ age group } \\
\hline $40<60$ years & $0.7 \pm 0.67$ & $0-2$ & $4.1 \pm 0.74$ & $3-5$ \\
\hline 60 and more years & $0.05 \pm 0.22$ & $0-1$ & $3.45 \pm 1$ & $2-5$ \\
\hline P. value & \multicolumn{2}{|c|}{ 0.001** } & \multicolumn{2}{|c|}{0.088} \\
\hline \multicolumn{5}{|l|}{ Gender } \\
\hline Male & $0.28 \pm 0.54$ & $0-2$ & $3.56 \pm 1$ & $2-5$ \\
\hline Female & $0.2 \pm 0.45$ & $0-1$ & $4.2 \pm 0.45$ & $4-5$ \\
\hline P. value & \multicolumn{2}{|c|}{0.821} & \multicolumn{2}{|c|}{0.161} \\
\hline \multicolumn{5}{|l|}{ Occupation } \\
\hline Working & $0.86 \pm 0.69$ & $0-2$ & $3.43 \pm 0.98$ & $2-5$ \\
\hline not working & $0.09 \pm 0.29$ & $0-1$ & $3.74 \pm 0.96$ & $2-5$ \\
\hline P. value & \multicolumn{2}{|c|}{$0.001 * *$} & \multicolumn{2}{|c|}{0.410} \\
\hline \multicolumn{5}{|l|}{ education level } \\
\hline Illiterate & $0.08 \pm 0.28$ & $0-1$ & $3.64 \pm 0.99$ & $2-5$ \\
\hline Write and Read & $1.25 \pm 0.5$ & $1-2$ & $3.75 \pm 0.96$ & $3-5$ \\
\hline primary education & $1 \pm 0$ & $1-1$ & $4 \pm 0$ & $4-4$ \\
\hline P. value & \multicolumn{2}{|c|}{$<0.001 * *$} & \multicolumn{2}{|c|}{0.932} \\
\hline
\end{tabular}

independent T-test $* *$ Significant difference at $p$. value $<0.01$

one way Anova ** Significant difference at p. value $<0.01$ 
Table (6): Comparison between study group regarding patients' complications pre-test and after 2 wk follow up from implementing nursing instructions $(n=60)$.

\begin{tabular}{|c|c|c|c|c|c|}
\hline \multirow{3}{*}{ Patients' complications } & \multicolumn{5}{|c|}{ Study $\operatorname{group}(\mathrm{n}=30)$} \\
\hline & \multicolumn{2}{|c|}{ pre test } & \multicolumn{2}{|c|}{ after 2wk follow-up } & \multirow{2}{*}{ P. value } \\
\hline & No. & $\%$ & No. & $\%$ & \\
\hline \multicolumn{6}{|l|}{ Urinary tract infection } \\
\hline Present & 11 & 36.7 & 3 & 10.0 & \multirow{2}{*}{$0.015^{*}$} \\
\hline Not present & 19 & 63.3 & 27 & 90.0 & \\
\hline \multicolumn{6}{|l|}{ Bleeding } \\
\hline Present & 12 & 40.0 & 5 & 16.7 & \multirow{2}{*}{$0.045^{*}$} \\
\hline Not present & 18 & 60.0 & 25 & 83.3 & \\
\hline \multicolumn{6}{|l|}{ Perforation } \\
\hline Not present & 30 & 100.0 & 30 & 100.0 & - \\
\hline \multicolumn{6}{|l|}{ Pain } \\
\hline Present & 15 & 50.0 & 5 & 16.7 & \multirow{2}{*}{$0.006 * *$} \\
\hline Not present & 15 & 50.0 & 25 & 83.3 & \\
\hline \multicolumn{6}{|l|}{ Fever } \\
\hline Present & 13 & 43.3 & 5 & 16.7 & \multirow{2}{*}{$0.024 *$} \\
\hline Not present & 17 & 56.7 & 25 & 83.3 & \\
\hline \multicolumn{6}{|l|}{ Incomplete resection } \\
\hline Present & 5 & 16.7 & 4 & 13.3 & \multirow{2}{*}{0.718} \\
\hline Not present & 25 & 83.3 & 26 & 86.7 & \\
\hline
\end{tabular}

- Fisher exact test $*$ Significant difference at $p$. value $<0.05, * *$ Significant difference at $p$. value $<0.01$

Table (7): Comparison between before and after application of nursing instructions for studied groups (study - control) regarding pain scale.

\begin{tabular}{|c|c|c|c|c|c|c|c|c|c|c|}
\hline \multirow{3}{*}{ Pain Scale } & \multicolumn{4}{|c|}{ study Group $(n=30)$} & \multirow{3}{*}{ P. value } & \multicolumn{4}{|c|}{ Control Group $(n=30)$} & \multirow{3}{*}{ P. value } \\
\hline & \multicolumn{2}{|c|}{ pre test } & \multicolumn{2}{|c|}{$\begin{array}{l}\text { after } 2 w k \\
\text { follow up }\end{array}$} & & \multicolumn{2}{|c|}{ pre test } & \multicolumn{2}{|c|}{$\begin{array}{l}\text { after } 2 w k \\
\text { follow up }\end{array}$} & \\
\hline & No & $\%$ & No & $\%$ & & No & $\%$ & No & $\%$ & \\
\hline No pain & 0 & 0.0 & 19 & 63.3 & \multirow{4}{*}{$<0.001 * *$} & 0 & 0.0 & 0 & 0.0 & \multirow{4}{*}{0.286} \\
\hline Mild pain & 0 & 0.0 & 11 & 36.7 & & 3 & 10.0 & 4 & 13.3 & \\
\hline Moderate pain & 26 & 86.7 & 0 & 0.0 & & 12 & 40.0 & 17 & 56.7 & \\
\hline Severe pain & 4 & 13.3 & 0 & 0.0 & & 15 & 50.0 & 9 & 30.0 & \\
\hline
\end{tabular}

- Chi-square test $* *$ Significant difference at p. value $<0.01$ 


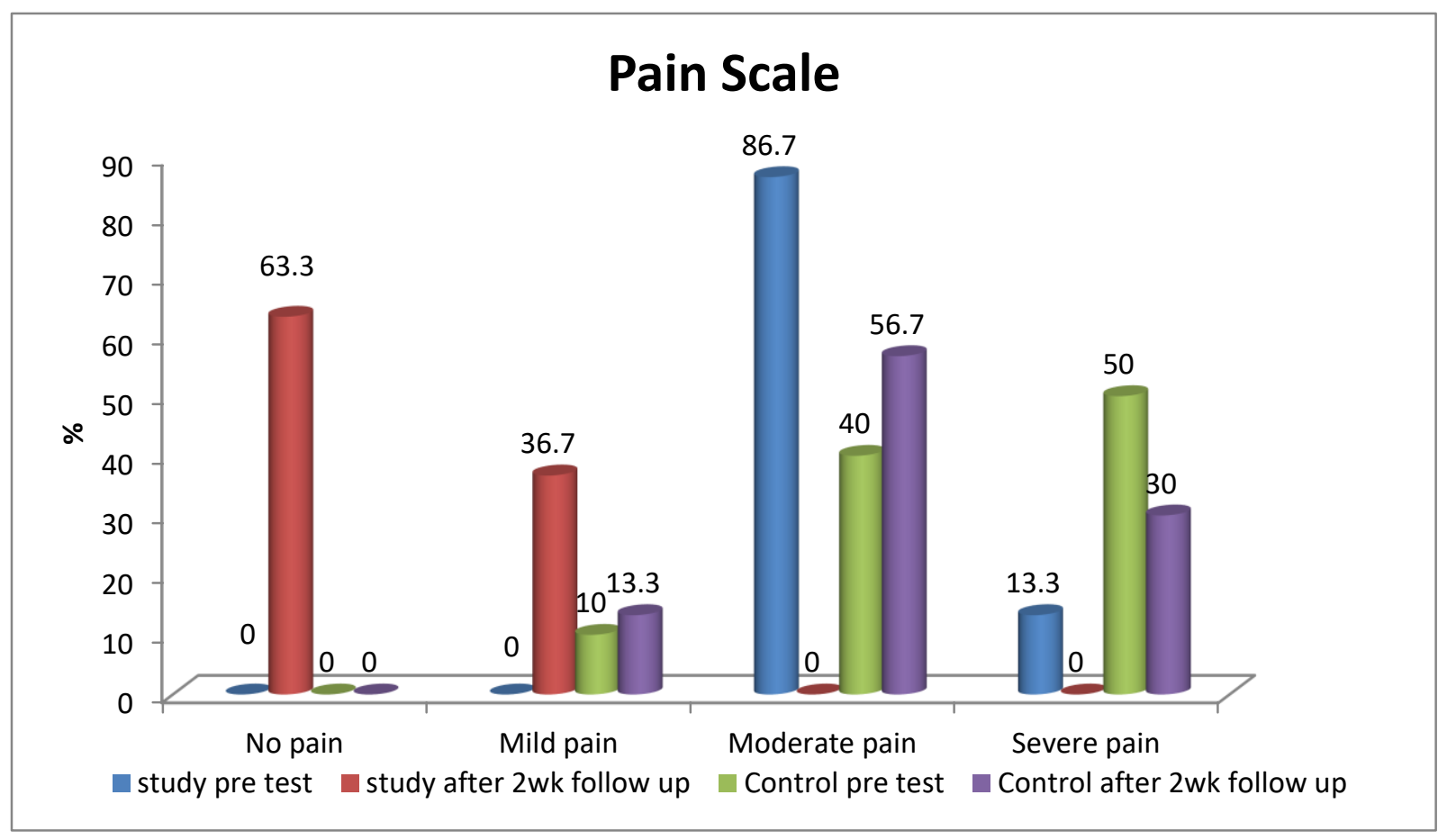

Fig (2): Comparison between before and after application of nursing instructions for studied groups (Study - Control) regarding pain scale.

Table (1): This table shows the highest percentage of the studied patients' ages more than 60 years old. Also there was predominance of male in both study\& control groups $(83.3 \%$ and $93.3 \%)$ respectively. As regard the marital status, the majority of patients in the study and control groups were married (100\% and 90\%) respectively. Concerning the patient's educational level, (83.3\% and $70 \%$ ) respectively in the study and control groups can't read \&write. In relation to patients' occupation, the majority of patient's in the study\& control groups were not working $(76.7 \%$ and $66.7 \%$ ) respectively.

Table (2): This table also reveals about $40 \%$ of the study groups have hypertension, $10.0 \%$ have diabetes, while in the control group about $6.7 \%$ have HTV and DM.

Table (3): This table illustrates there are statistically significant difference between the study and control group regarding level of patients' knowledge about transurethral resection of bladder tumor after implementing nursing instructions.

Table (4): This table illustrates the mean knowledge score, after application of the nursing instructions, the study group had higher mean knowledge score than the control group with statistically significant difference between both groups $\left(\mathrm{P}\right.$. value $\left.=0.001^{* *}\right)$. Fig (1): Reports that; before application of the nursing instructions the highest percentage of patients in the study group had unsatisfactory level of knowledge (13.3\%). While after application of nursing instructions, the majority of patients in the study group $(86.7 \%)$ had satisfactory level of knowledge with statistically significant difference $\left(\mathrm{P}=0.001^{* *}\right)$ before and after application of the designed nursing instructions.

Table (5): This table shows there was highly statistically significant relation was documented between patients' knowledge before instructions about bladder cancer and their socio demographic characteristics. Those who are educated had knowledge when compared with illiterate patients $(0.001)$, there was highly statistically significant relation between patients who were working and other weren't working (0.001), there was highly statistically significant relation between patients knowledge whose age more than sixty years and patients whose age ranged from 40-60 yrs (0.001) .

Table (6): This table shows there was statistically significant difference between study pre and follow up regarding complications (UTIs, pain, fever, bleeding) during hospitalization and 2 weeks from discharge (P. value $\left.<0.05^{*}\right)$.

Table (7): This table shows statistically significant difference between study group and control group as regards pain (P. value $<0.001 * *)$.

Fig (2): Illustrates that; there was statistically significant difference between study group and 
control group regarding pain scale $(\mathrm{P}$. value < $\left.0.001^{* *}\right)$.

\section{Discussion}

Transurethral resection of bladder tumor is one of the most commonly performed surgical procedures; Transurethral resection is the first-line treatment to diagnose, stage, and treat visible tumors (Gary, 2015). The outcome and complication rates are largely dependent on surgeon's skill and experience, the extent of surgery and indications of surgery. Complications following transurethral resection are rare but their consequences can often be life threatening as compared to other surgeries being performed routinely (Andres ,2018), so the perioperative care given by the nurse should cover the comprehensive needs of the patient, improving the patient's confidence to face surgery, and return to regular life activities(Brausi ,2016) .

The Aims of this study were; to assess patient's knowledge about transurethral resection of bladder tumor, to design nursing instructions for patients undergoing transurethral resection, and then to evaluate the effect of implementing nursing instructions on patients' outcomes.

\section{Socio demographic characteristics and health} habits

The present study showed that; the highest percentage of patients their ages more than 60 years old has bladder cancer. According to the studies which were carried out by Bulent Gunlusoy et al., (2015) who mentioned that the mean age of the patients $\geq 60$ yrs. with bladder cancer mean age was 71.1 7.5. Also, Volkan Sen et al., (2015) reported that, bladder cancer are very common in older adults. In present study the majority of the studied patients were males. In accordance with this study result, Babjuk (2017) which revealed that bladder cancer were present among males more than females.

Regarding medical history, more than two fifth of subjects in the study group were having hypertension and less than fifth of the control group were having hypertension, while less than fifth of the study group and the control groups were having diabetes. This finding was congruent with Zhu et al., (2013) who mentioned that a history of diabetes mellitus (DM) may be associated with an increased risk of bladder cancer. In the same context, Kok Victor et al., (2018) stated that positive association between hypertension and urinary bladder cancer.

\section{Level for patients' knowledge about bladder} cancer and transurethral resection:

The present study mentioned that, there are statistically significant difference between study and control group after implementing nursing instructions as regard knowledge level of patients about bladder cancer and transurethral resection. It's important to assess knowledge of patients because post treatment care included catheter care, diet and physical therapy affect positively on patients' outcomes and reduce incidence of complications as cleared in this study, the complications of study group decreased with following nursing instructions. However, after application of the nursing instructions, study group patients had a highly significant improvement than those of control ones in relation to all items of knowledge.

\section{Complications following transurethral resection}

The present study showed statistically significant difference between study and control groups as regard surgical complications, such as bleeding from discharge and after 2 weeks, this result in agreement with Roger et al., (2015) who mentioned that bleeding complications have a reported occurrence rate of $1-4 \%$. Interestingly, the risk of bleeding appears to be rising over time, and this may be due to the increased use of antiplatelet agents for prevention of cardiovascular events. Severe bleeding tends to be associated with larger tumors and early deep bladder perforations. Urinary tract infection during hospitalization and after 2 wks from discharge in agreement with Appell et al., (2015) who mentioned that the incidence of UTI after TURBT is very variable, at $2-39 \%$ attributed the high incidence of bacteriuria (39\%) after 90 TURBTs to high rates of bacterial colonization of the tumor $(63 \%)$. chronic disease such as diabetes and smoking was observed as the important patient-related risk factor responsible for postoperative infection. Also the present study reported statistically significant difference between study and control groups as regard pain from discharge and after 2 weeks in agreement with Wang et al., (2015) who stated that the most common complications was pain $(3.0 \%)$.

It is the fact that study documented that the nurse play a vital role in post treatment care and giving education to patients about catheter care, diet, medications, physical therapy, prevention of infection and others complications in patients with trans-urethral resection of bladder tumor and identification of early signs of complications. The qualified care nurse must be integrating theoretical knowledge, assessment skills, and problem solving ability to provide optimal nursing care and maintain high quality outcomes for patients undergoing TURBTs.

We can finally conclude that, the nursing instructions for patients undergoing trans-urethral resection of bladder tumor achieved its objectives by improving patients' knowledge and reducing postoperative complications. 


\section{Conclusions}

Patients' knowledge regarding post treatment care as (catheter care, diet and fluid intake) was inadequate. So a specialized nursing instruction was designed, implemented and evaluated. Study group showed improvement in knowledge and decreased incidence of complications while control group showed increase in complications such as bleeding, urinary tract infection and incomplete resection.

\section{Recommendations}

Based on the findings of the present study the

following recommendations are suggested:

1- Pamphlets and simple illustration booklets should be available for patients to provide them with simple explanation about TUR-BT which will be reflected on better outcomes.

2- Continued nursing education and in-service training programs at Urology department should be organized within Assiut University Hospital administration and equipped with the necessary educational facilities and materials necessary to upgrade the knowledge and skills of practicing nurses, which will be reflected on better outcome and service for in patients undergoing transurethral resection.

3- Replication of the study on a larger probability sample in different geographical areas in Egypt to figure out the main aspects of these problems.

\section{References}

1. Alschibaj, U., Paul. A., (2015): Transurethral resection for bladder cancer current developments,vol.44, no.5, S. Pp. 499-504.

2. Al-Zalabani A., Stewart K., Wesselius A., (2016): "Modifiable risk factors for the prevention of bladder cancer: a systematic review of meta-analyses," European Journal of Epidemiology, vol. 31, no. 9, Pp. 811-851.

3. Amr S., Dawson R., Saleh D., (2014): "Agricultural workers and urinary bladder cancer risk in Egypt", Archives of Environmental \& Occupational Health, vol. 69, Pp. 3-10.

4. Amr S., Loffredo C., Kallakury B., (2015): "Adenocarcinoma of the urinary bladder in Egypt: potential risk factors", World Journal of Nephrology and Urology, vol. 4, no. 3, Pp. 227231.

5. Antoni S., Ferlay J., Soerjomataram I., (2017): "Bladder cancer incidence and mortality: a global overview and recent trends", European Urology, vol. 71, no. 1, Pp. 96-108.

6. Babjuk M., Oosterlinck W., Sylvester R., (2015): EAU guidelines on non-muscle-invasive urothelial carcinoma of the bladder, Eur Urol ,vol.59 ,Pp. 997-1008.
7. Bajorin D., (2014): Tumors of the kidney, bladder, ureters, and renal pelvis, chapter5, $24^{\text {th }}$ ed., Pp. 1120-1135.

8. Bochner B., Kattan M., \& Vora K., (2015): "Postoperative monogram predicting risk of recurrence after radical cystectomy for bladder cancer," Journal of Clinical Oncology, vol. 24, no. 24, Pp. 3967-3972.

9. Burger M., Catto J., Dalbagni G., (2013): "Epidemiology and risk factors of urothelial bladder cancer," European Urology, vol. 63, no. 2, Pp. 234-241.

10. Chatterton K., Bugeja P., Challacombe B., (2016): Nurses' experience establishing a nurseled bladder cancer surveillance flexible cystoscopy service, J Urol. , vol. 28, Issue 3, Pp. 53-59.

11. Daugherty S., Lacey J., \& Silverman D., (2013): "Reproductive factors and menopausal hormone therapy and bladder cancer risk in the NIH-AARP Diet and Health Study," International Journal of Cancer, vol. 133, no. 2, Pp. 462-472.

12. Fajkovic H., Halpern J., Cha E., (2014): "Impact of gender on bladder cancer incidence, staging, and prognosis," World Journal of Urology, vol. 29, no. 4, Pp. 457-463.

13. Fernández M., López J., Vivaldi B., (2016): Long-term impact of arsenic in drinking water on bladder cancer health care and mortality rates 20 years after end of exposure. J Urol, vol.187, Issue 3, Pp. 4456-4489.

14. Gregg R., Justin, Wang L., Cohen P., Sun D., (2016) : "Seminar sand Original Investigations", Vol. 23, Issue 2, Pp. 8198 - 8203.

15. Gupta M., Jain R., Kapoor K., Srivastava A., (2017): "Impact of age and gender on the clinicopathological characteristics of bladder cancer" Indian Journal of Urology, vol. 25, no. 2, Pp. 207.

16. Hayat M., Howlader N., Reichman M., (2014): Cancer statistics, trends, and multiple primary cancer analyses from the Surveillance, JUrol, Vol. 32, Issue 2, Pp. $367-377$.

17. Hemelt M., Yamamoto H., Cheng K., \& Zeegers M., (2017): "The effect of smoking on the male excess of bladder cancer: a metaanalysis and geographical analyses," International Journal of Cancer, vol. 124, no. 2, Pp. 412-419.

18. Horstmann R., Witthuhn M., Stenzl A., (2015): "Gender-specific differences in bladder cancer: a retrospective analysis," Gender Medicine, vol. 5, no. 4, Pp. 385-394.

19. Hsu J., Xu D., (2013): "Decreased tumorigenesis and mortality from bladder cancer 
in mice lacking urothelial androgen receptor," The American Journal of Pathology, vol. 182, no. 5, Pp. 1811-1820.

20. Kamat A., \& Huri E., (2017): "What is new in non-muscle-invasive bladder cancer in 2016?" Turkish Journal of Urology, vol. 43, no. 1, Pp. 9-13.

21. Kok V., Zhang H., Lin C., Huang S., (2016): "Short term complications from transurethral resection of bladder tumor", Vol. 123, Issue 2, Pp. 109-115.

22. Koo V., McMahon J., Young M., (2013): Audit of nurse-led lower urinary tract symptoms clinic: lessons and challenges for practice,vol.21, Issue 2, Pp. 72-77.

23. Lamb B., Allchorne P., Sevdalis, Vincent C., \& Green (2016): The role of the urology clinical nurse specialist in the multidisciplinary team meeting, J. Urol., vol. 5, Issue 3,Pp. 59-64.

24. Loughlin K., (2017): Complications of urologic surgery and practice, chapter 4, 5th ed., Pp.786799.

25. Mallin K., David P., Carroll M., (2015): "Transitional cell carcinoma of the bladder: racial and gender disparities in survival, stage and grade", The Journal of Urology, vol. 185, no. 5, Pp. 1631-1636.

26. McGaughan E., Parahoo K., Thompson K., \& Reid S., (2014): Patients' satisfaction with a community-based, nurse-led bladder cancer assessment clinic, J Urol. ,vol. 27, Issue 3, Pp. 14-20 .

27. Morales S., Grill R., Svateka S., (2016): "Finasteride reduces risk of bladder cancer in a large prospective screening study," European Urology, vol. 69, no. 3, Pp. 407-410.

28. Mungan L., Kiemeney J., Dijck H., (2015): "Gender differences in stage distribution of bladder cancer” ,Urology, vol. 55, no. 3, Pp. 368371.

29. Otto M., May H., Fritsch (2012): “Analysis of sex differences in cancer-specific survival and perioperative mortality following radical cystectomy: results of a large German multicenter study of nearly 2500 patients with urothelial carcinoma of the bladder" Gender Medicine, vol. 9, no. 6, Pp. 481-489.

30. Pashos C., Botteman M., Laskin B., Redaelli A., (2013): Bladder cancer epidemiology, diagnosis, and management, cancer Practice,2nd ed., chapter 27, Pp.10-22.

31. Payandeh M., Sadeghi M., Edris S., (2016): Characteristics of patients with transitional cell carcinoma of the urinary bladder in European Association of urology Guidelines on the management of urinary and male genital tract infections, chapter 4,4th ed., Pp. 68-269.

32. Prizment K., \& Folsom (2015): "Reproductive risk factors for incident bladder cancer: Iowa Women's Health Study" International Journal of Cancer, vol. 120, no. 5, Pp. 1093-1098.

33. Ruder A., Carreon T., Ward E., (2015): Bladder cancer, Clinical occupational and environmental medicine, chapter 5, 2nd ed., Pp. 66-757.

34. Schultz H., (2011): Practical and legal implications of nurse practitioners and physician assistants in cystoscopy. Urol. vol. 31, Issue 3, Pp.355-358.

35. Shariat S., Favaretto R., Gupta A., (2015): "Gender differences in radical nephroureterectomy for upper tract urothelial carcinoma," World Journal of Urology, vol. 29, no. 4, Pp. 481-486. 